\title{
The effect of radiographic vertebral body and intervertebral disc wedging on curve progression in idiopathic scoliosis
}

\author{
R Volz ${ }^{*}$, LA Dolan, F Masrouha, SL Weinstein \\ From 9th International Conference on Conservative Management of Spinal Deformities - SOSORT 2012 \\ Annual Meeting \\ Milan, Italy. 10-12 May 2012
}

\section{Background}

Wedging of the apical vertebral body and the intervertebral disc are well-known characteristics of adolescent idiopathic scoliosis (AIS). Development of AIS may be secondary to vertebral wedging caused by primary abnormalities of the vertebral growth plate. Several studies have examined the relationship of vertebral body and disc wedging with scoliosis curve progression.

\section{Aim}

To estimate the reproducibility of apical vertebral and disc wedging, the correlation between wedging and Cobb angle, and the role of vertebral wedging in curve progression after skeletal maturity.

\section{Methods}

Baseline and 30-year follow-up x-rays from 56 AIS patients were evaluated. Wedging measurements included apical vertebral body height ratios (VBHR), apical vertebral body angles (VBA) and apical intervertebral disc wedging angles (IVDA). Intra- and inter-rater reliability was estimated using 2 readers and a subset of 20 curves. Multivariate regression estimated the contribution of wedging to prediction of curve progression.

\section{Results}

Intra-rater tolerance limits were: VBHR $\pm 12 \%$; VBA $\pm 7^{\circ}$; IVDA $\pm 7^{\circ}$. Inter-rater tolerance limits were significantly larger: VBHR $\pm 23 \%$; VBA $\pm 11^{\circ}$; IVDA $\pm 11^{\circ}$. Cobb angles were moderately correlated with wedging at baseline (VBHR -0.51; VBA 0.46; IVDA 0.40) and with the VBHR at follow-up (-0.65). Average curve progression

University of lowa, IA, USA was $18^{\circ}$ (range $\left.-11^{\circ}-126^{\circ}\right)$. The average change in VBHR over time was $\sim 5 \%$. Adding VBHR to a regression equation including baseline Cobb angle, age, Risser and years of follow-up improved prediction of the future Cobb angle (increase in adjusted R2 from 0.65 to 0.71 ).

\section{Conclusions}

This study provides tolerance limits to judge if a true change in apical vertebral or apical disc wedging has occurred. These limits should be considered when evaluating bracing or other procedures which potentially unload the spine and affect wedging. Wedging measured using vertebral height ratios was much more reliable than when measured using angles. Despite the average curve progression of $18^{\circ}$, there was no appreciable change in vertebral wedging over time. Clinicians and researchers should consider including vertebral height ratios when estimating long-term curve progression in AIS patients.

Published: 3 June 2013

\section{References}

1. Grivas TB, Vasiliadis E, Malakasis M, Mouzakis V, Segos D: Intervertebral disc biomechanics in the pathogenesis of idiopathic scoliosis. Stud Health Technol Inform 2006, 123:80-83.

2. Modi HN, Suh SW, Song HR, Yang JH, Kim HJ, Modi CH: Differential wedging of vertebral body and intervertebral disc in thoracic and lumbar spine in adolescent idiopathic scoliosis - A cross sectional study in 150 patients. Scoliosis 2008, 3:11.

3. Will RE, Stokes IA, Qiu X, Walker MR, Sanders JO: Cobb angle progression in adolescent scoliosis begins at the intervertebral disc. Spine (Phila Pa 1976) 2009, 34(25):2782-2786.

doi:10.1186/1748-7161-8-S1-038

Cite this article as: Volz et al:: The effect of radiographic vertebral body and intervertebral disc wedging on curve progression in idiopathic scoliosis. Scoliosis 2013 8(Suppl 1):O38.

@ 2013 Volz et al; licensee BioMed Central Ltd. This is an Open Access article distributed under the terms of the Creative Commons 